\title{
СТРАХ И НЕНАВИСТЬ В ГОРОДЕ ДРУЖБЫ И СОГЛАСИЯ. ГОРОД-ПОСРЕДНИК МАНЬЧЖОУЛИ И ЕГО ВЛИЯНИЕ НА РОССИЙСКОЕ ВОСПРИЯТИЕ КИТАЙСКОЙ МИГРАЦИИ
}

\begin{abstract}
Статья посвящена вопросу о том, какую роль играет опыт приграничного города-посредника в формулировании тревожных прогнозов относительно последствий миграции. В этом вопросе два аспекта- когнитивный и культурный. Ответ на него автор дает, опираясь на этнографический материал, собранный в городе-посреднике на российско-китайской границе. Успехи китайских региональных властей по созданию городовпосредников вдоль границы (с открытыми торговыми площадками, ориентированными на русских предпринимателей и надеждой на совместную жизнь), должны были рассеять все сомнения и «разоружить» тревожную память о советско-китайской конфронтации. Однако успех приграничного урбанизма в регионе привел к резкому росту опасений. Сегодня стоит говорить не столько об усилении старых фобий, сколько о появлении новых. Возникшие на границе города-посредники попали в ловушку собственной мимикрии под воображаемую модель российского города. Их приграничная локализация и ориентация на Россию сделали возможным экстраполяцию опыта совместной жизни россиян с китайскими предпринимателями на возможные сценарии развития Сибири и Дальнего Востока. В этих экстраполяциях соединены воедино две вещи-тревога по поводу стремительно беднеющего региона и массовое узнавание собственных страхов перед «пробуждением китайского дракона» у границ России. В статье предполагается, что массовые представления относительно перспектив китайской миграции в данном регионе формируются на основе негативного опыта, укоренённого в конкретном месте. Это знание не просто присутствует в качестве фона, оно играет ключевую роль в «эмпирическом подтверждении» латентных и открытых тревог по поводу истинных мотиваций китайских мигрантов.
\end{abstract}

Иван Олегович Пешков- PhD, доцент, институт общественных наук, РАНХиГС, Москва, Россия. Электронная почта: ivanpeshkov2007@ya.ru 
Ключевые слова: миграция, приграничный урбанизм, Россия, Китай DOI: 10.17323/727-0634-2020-18-4-609-624

Специфика приграничной урбанизации на восточных границах России состоит в возникновении с китайской стороны границы новых экстерриториальных городских пространств, соединяющих общую социалистическую эстетику и неолиберальную надежду на лучшую жизнь региона. Эти маленькие фабрики современности и обмена, благодаря своей локализации и сознательному имиджу амбивалентного места (одинаково чуждого и Китаю, и России) сыграли важную роль в массовом осмыслении китайской миграции. Казалось бы, ситуация предельно проста и предсказуема. Именно успехи китайских региональных властей по созданию городов-посредников вдоль границы (с открытыми торговыми площадками, ориентированными на русских предпринимателей и надеждой на совместную жизнь), должны были рассеять все сомнения и «разоружить» тревожную память о советскокитайской конфронтации и старые мифы. Но не все так просто, как кажется на первый взгляд. Успех приграничного урбанизма в регионе привел к резкому усилению опасений. Мы можем говорить не только об усилении старых тревог по поводу экспансии восточного соседа, но и появлении новых. Приграничные фантомы «успеха и дружбы» были восприняты как вычурная вуаль, скрывающая, по мнению жителей приграничных регионов России, «настоящее» лицо Китая- двуличное, непонятное и опасное. Их приграничная локализация и ориентация на Россию сделали возможным экстраполяцию опыта совместной жизни россиян с китайскими предпринимателями на возможные сценарии развития Сибири и Дальнего Востока. В этих экстраполяциях соединены воедино две вещи-тревога по поводу стремительно беднеющего региона и массовое узнавание собственных страхов перед «пробуждением китайского дракона» у границ России.

Почему искренние и эффективные попытки региональных властей северо-востока Китая создать пространства торговли и приятного отдыха привели к настороженности и недоверию по поводу настоящих мотивов китайской стороны? Почему негативный опыт с отдельными предпринимателями стал ключом к пониманию «реальной ситуации в регионе»? Какова роль китайского города-посредника в усилении тревоги по поводу будущего приграничных регионов Дальнего Востока? Я полагаю, что массовые представления относительно перспектив китайской миграции в данном регионе формируются на основе негативного опыта, укоренённого в конкретном месте. Локальное знание об «истинном лице Китая» проецируется на ближайшее будущее. Данное знание не просто присутствует в качестве фона, оно играет ключевую роль в «эмпирическом подтверждении» латентных и открытых тревог по поводу истинных мотиваций китайских мигрантов. Казалось бы, практики освоения пространства 
города-посредника должны способствовать преодолению стереотипов и формированию трансграничных сообществ. Однако ожидания неизбежных негативных последствий этому препятствуют.

Выбор города-посредника Маньчжоули продиктован несколькими причинами: масштабом торговли, относительной отдаленностью от больших городов и амбицией городских властей превратить поселок железнодорожников в царство неоновых огней и круглосуточной торговли. Сочетание этих факторов привело к столкновению гостеприимства и анонимности приграничного города с растущими опасениями по поводу китайской активности в приграничных регионах Дальнего Востока. Статья основывается на анализе 24 неструктурированных интервью, взятых у китайских и российских предпринимателей в период 2012-2019 в Восточной Сибири (Иркутск, Улан-Удэ) и приграничных городах Внутренней Монголии КНР (Маньчжоули, Хайлар). Интервью проводились на русском, китайском и монгольском языках.

Вместо того, чтобы увидеть в сомнениях приграничных жителей большие истории о «неподготовленности к культуре развития», «страхов перед глобализацией» или новые формы антикитайских фобий, в статье предлагается более простой подход: отнестись к тревогам как к самодостаточным сообщениям и понять их причины, динамику и пространственные контексты. Он позволяет не только скорректировать априорный образ неподготовленности жителей Дальнего Востока к новым формам приграничного сотрудничества, но и обратить внимание на императив поиска компромисса между возможностями приграничного обмена и безопасностью экономического сотрудничества для приграничных регионов. С точки зрения городских исследований описанный в статье случай обращает внимание на неожиданные риски гибридных городских пространств, усиливающих тревогу и опасения в, казалось бы, идеальном месте «дружбы и согласия».

\section{Что остается в Маньчжурском Лас-Berace?}

Около получаса пути (18 километров), отделяющих приграничный российский Забайкальск от приграничного китайского Маньчжоули, кажется путешествием в другую эпоху. Бедный забайкальский поселок с устаревшей инфраструктурой и коровами на улицах резко контрастирует с суперсовременным городом бизнеса и круглосуточного досуга. В регионе российско-китайская граница имеет только одну витрину, и этой витриной является Маньчжоули. Контраст усиливается и по причине изменения качества инфраструктуры сразу после пересечения границы. Современные автострады и логистические центры не оставляют сомнения в том, кто определяет стандарты развития в российско-китайском сотрудничестве.

Первая станция полосы отчуждения КВЖД- Маньчжурия на протяжении длительной истории была небольшим поселком российских 
и китайских железнодорожников, больше напоминающим деревню, чем город (Urbansky 2012). Город успел побывать форпостом российского колониального освоения Маньчжурии, японской приграничной заставой, местом оживленного обмена между двумя «братскими социалистическими странами» и крепостью, обороняющей китайские рубежи от северного соседа. Новая эпоха в истории города началась 16 апреля 1983 г., когда после полутора десятилетий экономической изоляции была возобновлена торговля между приграничными регионами СССР (Восточная Сибирь и Дальний Восток) и КНР (провинцией Хэйлунцзян и Автономным Районом Внутренняя Монголия). Спустя два года (август 1985) для приграничного обмена открыты несколько пар городов: Манчжурия-Забайкальск, Хэйхе-Благовещенск, Суйфеньхе-Гродеково и Тунцзян-Нижнеленинское (Базаров, Ганжуров 2002:59). С 1991 г. города-бастионы советско-китайской границы окончательно превращаются в формальные и неформальные зоны приграничной торговли.

Открытие границы определило судьбу Маньчжоули, который за короткое время превращается из провинциального бедного поселка в основной полюс развития российско-китайских экономических отношений. На месте китайско-русского поселка вырастает современный торговый район, свободно использующий цитаты из советской символики и архитектуры. Маньчжоули представляет собой важнейший транспортный узел российско-китайской торговли (60\% экспорта в Россию) и специфический фантом суперсовременной жизни, ориентированный на российских и китайских туристов (Zhang Ping-Yu et al. 2002). Реплики наиболее известных советских памятников размещаются рядом с макетами церквей, собранные на открытом пространстве огромные матрешки соседствуют с цитатами из символического ряда торговых городов Персидского залива, создавая вместе эффект экстерриториальности и вневременности.

Согласно интервью, местные жители относятся к этим фантомам города успеха и развития с ироничным равнодушием. Такое отношение не следует рассматривать как неготовность к современности, скорее за ним стоит более глубокое понимание ее локальных форм. Имитация мегагорода в одном торговом районе может справедливо восприниматься как фасад, приграничная показуха. Семиотическую перегруженность символа мега-города в маленьком городе усиливает, с одной стороны, расползание бедности, традиционной для этой части Китая, а с другой-инвестиционный бум в отдельных микрорайонах. Поэтому сомнения в материализации «китайского чуда» выглядят вполне оправданными. Отдавая должное модернизации инфраструктуры и связанным с ней возможностям для досуга и потребления, гости с Дальнего Востока и из Иркутской области видят фантомный характер этих городских пространств.

Фантомный характер города-посредника усиливается его приграничной локализацией. Для приезжих из глубинки огни большого города рядом 
с границей - это немыслимые возможности, нечто, выходящее далеко за пределы мечты об удачной сделке или недорогом отдыхе. Одна из респондентов Саяны Намсараевой с иронией описала посещение косметических салонов и свободное время в Маньчжоули: «Приезжаю Бабой-Ягой, уезжаю Василисой Прекрасной» (Namsaraieva 2016: 117). Попадая сюда, они могут вырваться из круговорота элементарного выживания и погрузиться в мир головокружительных предложений, многообещающих встреч и смены идентичностей. Здесь возможны легкие деньги, случайные связи, неожиданные знакомства, а также социальные и гендерные роли, непредставимые в других местах. Российские предприниматели наслаждались здесь свободой не-места, следуя духу американской поговорки What happens in Vegas, stays in Vegas! Знакомства, вечеринки, конфликты, романы- жизнь Маньчжурии до появления эффектов ослабления рубля (2016 г.) кипела страстями. Но городу-призраку не была уготована судьба Тихуаны, с ее ореолом тайны, свободы и романтизированной опасности. Будущее Маньчжоули было предопределено тревогой по поводу китайской активности в регионе.

В 2010 г. сибирские газеты и интернет-порталы сообщили о фактах физической агрессии на рынках приграничного города-посредника. Эти факты преподнесены как свидетельство китайских претензий на господство в Сибири. Предлагаемый масштаб (не отдельные продавцы, а «китайцы») и контекст делали из отдельных частных случаев насилия нечто большее, чем экзальтированное поведение отдельных торговцев, надышавшихся атмосферой анонимности, легких денег и гедонистической надеждой на круглосуточные развлечения. Рядовые жители Восточной Сибири стали проецировать рассказы об агрессивном поведении китайцев в Маньчжурии на китайский сегмент местного рынка. Сибиряки ожидали «пробуждения» китайцев как претендентов на власть уже в их собственных городах. Так 40-летний иркутянин выразил свою «озабоченность» подъемом Китая: «Все говорят, что в Маньчжурии небезопасно. У нас уже как в Маньчжурке китайцы совсем озверели. Делают на рынке, что хотят. Могут ударить, если не купишь». Китайский город, созданный с целью развития приграничного сотрудничества, неожиданно стал предметом страха перед китайской агрессией, воплощением которой считались китайские мигранты. Жительница приграничного поселка так выразила свои (по моим наблюдениям, вполне типичные) сомнения в успехе Маньчжоули: «Они все построили за наши деньги. Я помню Манчжурку деревней хуже Забайкальска, а теперь... Нужно осторожно с ними [китайцุами]».

\section{«Капиталисты поневоле» в городе-посреднике}

В академической литературе города-посредники этого региона редко оказываются в фокусе внимания. Они всплывают в исследованиях либо в виде символа окончания российского века на Востоке, либо в контексте 
столкновения несовместимых представлений о перспективах развития и ностальгии по упорядоченному миру приграничного социализма (Бийе 2014). Теоретическое осмысление этого феномена еще впереди. Среди проблем, ждущих разработки, можно выделить несовпадение голосов по обеим сторонам границы с реальными практиками совместной жизни, тезис о де-модернизации приграничных регионов России и априорное утверждение о несовпадении образов успеха у российских и китайских зрителей приграничного спектакля. В любом случае история приграничной урбанизации предстает здесь как история неудачи, резко контрастирующая с историями успеха похожих проектов в приграничных зонах Азии, Африки и Латинской Америки (Soi, Nugent 2018).

Несмотря на существенное различие в экономическом, демографическом и инфраструктурном потенциале приграничных территорий России и Китая, существует группа общих структурных проблем, истоки которых лежат в специальной политике по отношению к приграничным регионам, проводившейся в обеих странах в социалистический период. Социалистическая модернизация в таком регионе означала закрытую модель управления границей и эффективный государственный контроль над территорией и населением (Peshkov 2014). В условиях нарастающей советско-китайской конфронтации (со второй половины 1950-х гг.) это вело к милитаризации приграничных территорий, организации приграничного пространства как военно-промышленной базы, жесткому контролю над притоком населения в приграничные районы, а также особенное «внимание» государства к трансграничным сообществам (Peshkov 2011). Теперь же в регионе начинает доминировать именно пришлое население с новым географическим воображением, постепенно создающее новые формы локальности (Bille 2009; Peshkov 2014). В каждой из частей региона государственная политика форсированной индустриализации создала специфическую форму социальной организации, определяющую все стороны жизни приграничного населения: военно-индустриальный приграничный комплекс. Этот тип социальной структуры отличала абсолютная зависимость от государственной поддержки, что создавало ситуацию высоких социальных рисков после демилитаризации границы и реформирования промышленности.

Антропологические и социологические исследования переходного периода в обеих странах показывают, сколь сложной была адаптация населения к новым (рыночным) формам социальной организации (Ericson 2000; Волков 2005; Александров 1999; Хамфри 2010). Следует заметить, что «старые формы» образуют сложную группу практик, где продолжение старого соседствует с изобретением, цитированием и имитацией символов и социальных моделей предыдущего периода. Смешанный характер процессов трансформации во многом определил и характер приграничных обменов в регионе. Здесь преобладают малые формы экономической активности, часто дополняющего характера (Ryzhova 2008: 328). Это означает, 
что большинство участников приграничного обмена продолжает играть прежние социальные роли и сохраняет «старый» социальный статус (учителя, военные пенсионеры, рабочие). Богатая инфраструктура приграничного обмена (легального и нелегального) является фактором интеграции «старых» и новых форм экономической активности. Во многих случаях именно возможности приграничной торговли дают возможности продолжать прежние формы социальной и экономической активности. Что очень важно, так как эта структурная составляющая позволяет увидеть в социальном регрессе приграничных территорий Восточной Сибири и в многолетнем процессе выталкивания рабочей силы из северо-восточного Китая очень похожие явления. Оба вызваны распадом системы организации границы (демилитаризация), сокращением коллективных форм сельскохозяйственного труда и сложной адаптацией старых промышленных баз к новым условиям (Хамфри 2010).

Открытие границ и резкий рост мобильности приграничного населения приводит к попыткам изобретения трансграничности и переинтерпретации приграничных регионов-бастионов в категориях открытости, гибридности и особых связей. Китайская сторона с начала 90-х гг. воспринимает границу как ресурс не только экономического, но и социокультурного развития. Город-посредник в регионе как нельзя лучше символизирует новый китайский урбанизм, соединяющий экономику ожиданий с типичным для Китая превращением городских пространств в места материализации утопии и обучения новым моделям жизни (Duafang Lu 2006). Описывая пространства современных городов, исследователи все чаще используют понятия текучести, прозрачности и проходимости (Bauman 2000; Lee 2005). Для описания постсоциалистической периферии, не говоря уже о менее развитых странах, более адекватным кажется понятие дискретной современности. Ее суть состоит в попытках решить проблемы неоконченной индустриализации постиндустриальными методами (Peshkov 2011). Эта гибридная ситуация ведет и к амбивалентности роли государства: оно продолжает выступать главным инициатором развития, отказываясь при этом от ответственности за открытый доступ к современным моделям жизни и моделям социальной безопасности. В результате современные города постсоциалистической периферии оказываются пересеченными границами современности и упадка. Возникающие новые режимы мобильности эксклюзивны, на старое разделение город-деревня накладывается жесткий водораздел между моделями жизни внутри городов и в пригородах. В этом контексте дискретная современность означает сознательное воспроизведение ниш отсталости или традиционности в центре городской жизни. Мигранты, жители неблагоустроенных районов, этно-сегменты товарно-вещевых рынков не выносятся на окраины, а становятся неотъемлемой частью городской жизни. Успех и неудача городского развития больше не исключают друг друга, а мирно друг с другом соседствуют. 
Город-посредник в китайской версии доводит эту тенденцию до предела. Он символизирует ультрасовременный урбанизм. Последний, как правило, представлен в одном районе (который и становится символом города), сложно связанным с жизнью остальных частей города. Ментальные карты туристов и местных жителей окончательно расходятся, словно речь о разных городах (Бийе 2014). Характер этой связи может меняться в зависимости от времени и места, но можно на примере города Маньчжоули выделить несколько важных аспектов. Пространство главного района организовано таким образом, что он символизирует Россию для китайцев и Китай для русских, соединяя две страны в пространстве общей (пост)социалистической эстетики и общих экономических интересов. Город-посредник в силу локализации и размеров не является глобальным городом, но представляет собой попытку его имитации в регионе. Приграничная локализация определяет и сезонный характер его функций: летом Маньчжоули предстает как китайская Россия для китайских туристов, в остальное время года- как русский Китай для туристов из России. Город-посредник выступает производителем услуг, нацеленных, как минимум на три группы: российских туристов (дешевые товары в комфортной обстановке), китайских туристов (настоящая Россия) и китайского правительства (город интенсивного трансграничного обмена). Однако реализовать эти стратегии трудно в силу целого ряда факторов: периферийная локализация соседних сибирских регионов, углубляющиеся экономические трудности России, а также появление новых логистических моделей, связанных с доступом к товарам западной промышленной базы (линия Урумчи-Бишкек-Иркутск) и бурным развитием интернет торговли c Китаем (Ryzhova 2018). В этих условиях судьба города напрямую зависит от согласования китайской «экономики ожиданий» (порождающей инвестиционную переоценку большинства проектов) с покупательной способностью населения сибирской периферии (падающей из-за сокращения дотаций из центра).

\section{Ожидания и опыт: опасные связи}

Вызов, с которым столкнулись российские предприниматели в приграничных городах, можно разделить на две части. Это освоение синкретической культурной среды и представления о перспективах развития сотрудничества/конкуренции в регионе. Эти части взаимосвязаны. Начнем с пространственных аспектов сложившейся ситуации. Почему городское пространство, созданное для производства эффектов объединения ради развития, приводит к обратным эффектам- настороженности и тревоге? Почему за несколько неуклюжими декорациями, созданными для манифестации дружбы и сотрудничества, респонденты увидели именно лицемерие и обман? Именно обманчивая похожесть города-посредника на знакомые 
респондентам сибирские города и его близость к границе привела к бесконечным цепочкам разочарований и опасений. Несмотря на русскоязычные надписи, музыку и вариации на тему русской кухни в ресторанах, действующие в городе-посреднике китайские стандарты, сертификаты и процедуры оказания медицинской помощи значительно отличаются от российских. Все это создавало у российских посетителей этого места ощущение низкого качества, которое не могли компенсировать низкие цены.

Второй аспект затрагивает процедуры обобщения тревожного опыта. Как производятся цепочки знания о будущем миграционных потоков? Беспокойство у респондентов вызывает практически все: никогда неспящий город в свете неонов на фоне руин постсоветского Забайкалья, изобилие товаров, китайские стандарты, низкие цены, добродушие или, напротив, напористость китайских торговцев, непонятная китайская водка, замаскированная под русскую китайская еда и даже китайские сексработницы. Но как образ торговой площадки оказался в глазах респондентов не просто символом национального характера китайцев, но и символом будущего приграничных регионов?

Неизбежная фасадность города-посредника и его запрограммированная неспособность реализовать свои обещания (быть чем-то большим, нежели подобие большого современного города) воспринимается как ключ к пониманию специфики китайского общества вообще. Скептики из больших и малых городов Восточной Сибири и Дальнего Востока экстраполировали «показуху» торговой площадки города-посредника на всю политику Китая, нацеленную на то, чтобы понравиться или удивить соседей. Другими словами, спектакль успешного приграничного модерна отбракован по Станиславскому: «Не верю»,- вот сжатое выражение чувств россиян по отношению к приграничным городским площадкам.

Анализ проведенных интервью показывает, что респонденты, отдавая дань уважения китайским успехам, смотрят на них более реалистично и спокойно, чем исследователи, восторгающиеся китайским экономическим чудом и искренне не понимающие, чем недовольны выходцы из небогатого российского региона. Систематически пользуясь транспортной и городской инфраструктурой, россияне видят, что приграничные фасады прикрывают непростую экономическую ситуацию в китайском приграничье, которое не может предложить ничего, кроме стремительно дорожающих услуг и товаров (в целом более или менее доступных и на местных рынках российского Дальнего Востока и Сибири).

Что касается китайской стороны, то здесь тоже имело место разочарование, хотя и совсем другой природы. Для китайцев архитектурные эксперименты на тему советского монументализма должны были создать атмосферу современности и порядка, а создание инфраструктуры никогда не спящего города было не чем иным, как рациональной попыткой обеспечить возможность досуга для богатых гостей. Но вместо богатых 
русских к ним приехали совсем другие люди. Основную массу приезжих составляли жители бедного и криминализированного Забайкалья, воспринимаемого китайцами как зона отсталости, социального регресса и опасности. Многие китайские предприниматели имели негативный опыт криминальной торговли в Сибири в 1990-е гг.; среди предпринимателей северо-востока Китая сильна память об ограблениях и убийствах родственников и друзей. С точки зрения китайцев, город производит «вкус дружбы», давая возможность наслаждаться российской архитектурой, совместным отдыхом в ресторанах с русской музыкой в обществе российских и украинских секс-работниц. По словам китайских респондентов, в город, кроме россиян, приезжает много богатых китайцев, покупающих более качественные товары и услуги, чем те, что достаются более бедным клиентам из России. На мой вопрос о признаках «русского» в Маньчжоули, респондент из центрального Китая перечислил следующее: памятник медведю и панде (символ российско-китайской дружбы), уличные фонари, улицы (по-видимому, имея в виду дома и надписи на русском), рестораны с русской музыкой и возможность контактов с русскими женщинами. Не видя проблем с безопасностью, он отметил проблемы с дружбой: китайцы и россияне объединены рынком, нужны друг другу для бизнеса, но не для дружбы.

Что касается геополитических импликаций бизнеса, они по-разному видятся по обеим сторонам границы. Описывая город-посредник как место обмана, лицемерия и агрессии, российские респонденты представляли себя героями, выдержавшими серьезное испытание. Но это испытание было чем-то большим, чем просто приключение в экзотическом месте. Оно одновременно воспринималось как образ будущего Забайкалья, не готового к конкуренции с решительными и аморальными торговцами из Китая. Трезвое видение фасадного характера китайской современности и острых социальных проблем, стоящих перед этой страной, лишь подстегивало страхи. Их ксенофобские высказывания по адресу китайцев имели однозначную локальную привязку. Иначе говоря, забайкальцы были рады богатым и образованным китайцам из Гонконга и Сингапура, но не имели никаких иллюзий по отношению к братьям по несчастью-жителям китайских приграничных регионов, готовым на все ради выживания.

Таким образом, причиной страхов является именно понимание фасадного характера китайского чуда. К новому витку страхов и негативных ожиданий ведет китайская экономическая активность в регионе, непосредственно ориентированная на Россию. Она воспринимается россиянами как агрессивное стремление заработать на потоках товаров, поставляемых с отдаленных индустриальных баз. Жители региона не думают, что миллионы китайцев захотят переселиться в их суровые края. Но они считают, что за меланхолической оппозицией «разруха versus фасады успеха» стоит более важное противоречие- между бедным и географически рассредоточенным 
населением их региона, с одной стороны, и массой «хищников китайского рынка», способных навязать свое превосходство, с другой.

В этой перспективе опыт площадки города-посредника не только является ключевым для «верификации» подобных опасений- сам этот опыт порождается шаткостью экономического положения региона. «Китайская угроза» в представлении местных жителей связана не с абстрактным вторжением Китая в Россию, а с конкретным опытом взаимодействия с вчерашними безработными и колхозниками из приграничных китайских регионов. С точки зрения моих респондентов, угрозу представляет собой, прежде всего, нынешняя форма сотрудничества, при которой у Сибири и Дальнего Востока мало шансов на достойное участие.

Говоря языком французской прагматической социологии, важно «осознать влияние институизированного (institué) на практики, без того, чтобы недооценивать силу институизирующего (instituant), которые неизбежно несут эти практики» (Барт и др. 2019:206). Первым моментом, на который здесь следует обратить внимание, являются новые формы соединений (рынок) и разъединений (безопасность) в приграничном регионе. Объединённые трансграничной торговлей и возможностями асимметрической структуры цен, жители приграничных районов России и Китая разъединяются не только гражданской принадлежностью, но и диаметрально разным пониманием последствий экономической интеграции. Это приводит к парадоксальным оценкам, когда личные выгоды приграничного развития рассматриваются людьми как несущественные на фоне более значимых процессов опасного включения региона в зону китайского влияния. В этой перспективе массовое вовлечение в рынок сопровождается активным запросом на возвращение государства. Второй момент- новые формы тревожной трансграничности, связанные с приходом нейрокапитализма в пространство хронического недоразвития и остановки модерна. Уход государства и перенос ответственности на людей, неизбежно приводит к резкому усилению тревог и паники. В российской ментальной географии вектор культуры и развития однозначно направлен с Запада на Восток: за исключением нескольких больших городов отдаление от центральной части является синонимом экономической отсталости и социального риска. Мысля в этой перспективе, жители региона воспринимают последний как зону экономического и культурного выживания, далекую даже от культурных центров Сибири. Уход государства и открытая граница с Китаем воспринимаются как новые формы незащищенности: внутренние и внешние, что резко усиливает тревожность по поводу приграничного сотрудничества. Страх и неуверенность являются ожидаемой реакцией человека, оставленного государством в пространстве отдаленности и недоразвития. Тревожные ожидания относительно нашествия китайских предпринимателей есть не что иное, как эмоциональная реакция на экономическую неподготовленность приграничных регионов для взаимовыгодного сотрудничества. 


\section{Заключение}

Процессы экономической и культурной глобализации заставляют по-новому взглянуть на приграничные регионы как точки интенсивного взаимодействия локальных и глобальных процессов, а также инструменты включения человеческого и физического капитала в сети международного обмена. Особенно интересен переход от «приграничного социализма» к «приграничному капитализму» в системе границ России и Китая. Здесь идет процесс трансформации приграничья, а именно, превращение изолированных и военизированных районов в места формальных и неформальных трансграничных контактов. В приграничных городах происходит специфическое преломление глобальных процессов.

Опыт города-посредника играет ключевую роль в формировании негативных ожиданий по поводу будущих миграционных процессов. Выгоды людей от открытости границ и мечта об усилении контроля над границами вовсе необязательно противоречат друг другу: вполне возможно представить попытки найти компромисс между возможностями приграничного обмена и безопасностью экономического сотрудничества. Опыт российско-китайского приграничья показывает, что без радикальных изменений социальной ситуации заманчивые возможности приграничного сотрудничества оборачиваются не более чем инструментом выживания в условиях нестабильности и риска. Именно отсюда проистекают надежды на усиление государственного контроля над приграничной экономикой и трансграничной миграцией.

После затяжного кризиса российской экономики ситуация на этом участке границы выглядит тупиковой: страхи российских предпринимателей сочетаются с сомнениями китайской стороны по поводу экономического потенциала депрессивного региона и неповоротливости российских региональных властей, не способных создать инфраструктуру пространства приграничного развития. Этот фактор нельзя не учитывать при планировании дальнейшего развития региона.

\section{Выражение признательности}

Исследование выполнено в рамках НИР «Пространственные и материальные аспекты азиатских моделей урбанизации».

\section{Список источников}

Александров Ю.Г. (1999) Переходная экономика: Российская версия. М.: ИВ РАН. Базаров Б.В, Ганжуров Д.П. (2002) Российско-китайские отнотения и роль регионов в восточной Сибири в их развитии. Иркутск: Оттиск. 
Барт Я., де Блик Д., Эртан Ж-Ф, Ланьо Э., Лемье С., Линар Д., Моро де Белланг С., Реми Р., Тром Д. (2019) Прагматическая социология: инструкция по применению. Сочиология власти, 2 (31): 176-216.

Бийе Ф. (2014) Современность в пространственном измерении: открытые рынки, герметичность и вертикальность в двух приграничных городах. Экономическая сочиология, (15): 76-96.

Волков В.В. (2005) Силовое предпринимательство. Экономико-социологический анализ. М.: ГУ-ВШЭ.

Хамфри К. (2010) Постсоветские трансформации в азиатской части России. Антропологические очерки. М.: Наталис.

Bauman Z. (2000) Liquid Modernity. Cambridge: Polity.

Bille F. (2009) Cooking the Mongol/Feeding the Han: Dietary and Ethnic Intersections in Inner Mongolia. Inner Asia, 11 (2):205-230.

Duafang Lu (2006) Remaking Chinese Urban Form: Modernity, Scarcity and Space, 1949 2005. London: Routledge.

Ericson R.E. (2000) The Post-Soviet Russian Economic System: An Industrial Feudalism? BOFIT Online, (8): 1-26.

Lee R. (2005) Bauman, Liquid Modernity and Dilemmas of Development. Thesis Eleven, (83): 61-77.

Lisheng D. (2005) China's Drive to Revitalize the Northeast, China Perspective. Available at: https://journals.openedition.org/chinaperspectives/462 (accessed 1 May 2020).

Namsaraieva S. (2016) Gender and Trade in Russian - China Border City Manzhouli. Russian Studies, (3): 94-120.

Naughton B. (2007) The Chinese economy. Transition and Growth. Cambridge: MIT Press.

Peshkov I. (2011) From 'Border Socialism' to'Border Capitalism'. Past Dependency in the Inner Asia Border Triangle. Sensus Historiae. Studia Interdyscyplinarne, III (2): 139-149.

Peshkov I. (2014) Usable Past for a Transbaikalian Borderline Town. 'Disarmament' of Memory and Geographical Imagination in Priargunsk. Inner Asia, (16): 95-115.

Ryzhova N. (2008) Informal Economy of Translocations. The Case of Twin City of Blagoveshensk-Heihe. Inner Asia, (10):323-351.

Ryzhova N. (2018) The Emergence of Cross-Border Electronic Commerce Creativity and Declining Trust. C. Humphrey (ed.) Trust and Mistrust in the Economies of the ChinaRussian Borderlands. Amsterdam: Amsterdam University Press: 229-250.

Soi I., Nugent P. (2018) Peripheral Urbanism in Africa: Border Towns and Twin Towns in Africa. Journal of Borderlands Studies, 32 (4): 535-556.

Urbansky S. (2012) A Very Orderly Friendship: The Sino-Soviet Border under the Alliance Regime, 1950-1960. Eurasia Border Review, (3): 35-53.

Zhang Ping-Yu, Ma Yan-ji, Yu Zhen-han (2002) Border port Manzhouli: Urban Function and Space Development. Chinese Geographical Science, 12 (4):315-320. 
Ivan Peshkov

\title{
FEAR AND HATE IN THE CITY OF FRIENDSHIP AND HARMONY. THE INTERMEDIARY CITY OF MANZHOULI AND ITS INFLUENCE ON PERCEPTIONS OF CHINESE MIGRATION IN RUSSIA
}

\begin{abstract}
The article explores the influence that an intermediary border town has in the formation of alarming forecasts about the consequences of migration. There are two aspects to this issue: cognitive and cultural. These aspects are examined through ethnographic data collected in the intermediary city of Manzhouli on the Russian-Chinese border. The success of Chinese regional authorities in creating intermediary cities along the border, with open marketplaces orientated towards Russian entrepreneurs and the hope of living together, should have dispelled all doubts and 'disarmed' the disturbing memory of Soviet-Chinese confrontations. However, the success of cross-border urbanism in the region has led to a considerable increase of concerns. Today it is worth talking not so much about the strengthening of old phobias, but about the emergence of new ones. The intermediary cities that have emerged on the border have fallen into the trap of their own mimicry under the imaginary model of the Russian city. Their border localization and focus on Russia made it possible to extrapolate the experience of living together with Chinese entrepreneurs to possible scenarios for the development of Siberia and the Far East. These extrapolations combine two matters: anxiety about the rapid impoverishment of the region and old fears of 'an awakening Chinese dragon' at the borders of Russia. The article assumes that mass perceptions of Chinese migration in this region are formed on the basis of negative experience rooted in a particular place. This knowledge is not just present in the background, it plays a key role in 'empirically confirming' latent and exposed concerns about the true motivations of Chinese migrants.
\end{abstract}

Keywords: migration, frontier urbanism, Russia, China

DOI: 10.17323/727-0634-2020-18-4-609-624

\section{References}

Aleksandrov Y.G. (1999) Perekhodnaya ekonomika: Rossiyskaya versiya [The transition Economy: Russian Version]. Moscow: IV RAN.

Bazarov B.V, Ganzhurov D. P. (2002) Rossiysko- kitayskie otnosheniya i rol' regionov v vostochnoy Sibiri v ikh razvitii [Russian-Chinese Relations and the Role of Regions in Eastern Siberia in their Development]. Irkutsk: Ottisk

Ivan Peshkov- PhD, Institute for Social Sciences, RANEPA, Moscow, Russian Federation. Email: ivanpeshkov2007@ya.ru 
Barthe Y., de Blik D., Heurtin J., Lagneau É., Lemieux C., Linhardt D., Moreau de Ballaing S., Rémy C, Trom D. (2019) Pragmaticheskaya sotsiologiya: instruktsiya po primeneniyu [Pragmatic Sociology: Instructions for Use]. Sotsiologiya vlasti [Sociology of Power], 31 (2): 176-216.

Bauman Z. (2000) Liquid Modernity. Cambridge: Polity.

Bille F. (2009) Cooking the Mongol/feeding the Han: Dietary and Ethnic Intersections in Inner Mongolia. Inner Asia, 11 (2): 205-230.

Bille F. (2014) Sovremennost' v prostranstvennom izmerenii: otkrytye rynki, germetichnost' i vertikal'nost' v dvukh prigranichnykh gorodakh [Surface Modernity: Open-Air Market, Containment and Vertycality in Two Border Towns of Russia and China]. Ekonomicheskaya sotsiologiya [Economic Sociology], (15): 76-96.

Duafang Lu (2006) Remaking Chinese Urban Form: Modernity, Scarcity and Space, 1949_ 2005. London: Routledge.

Ericson R.E. (2000) The Post-Soviet Russian Economic System: An Industrial Feudalism? BOFIT Online, (8): 1-26.

Humphrey C. (2010) Postsovetskie transformatsii v aziatskoy chasti Rossii. Antropologicheskie ocherki [Post-Soviet Transitions in the Asian Part of Russia. An Anthropological Study]. Moscow: Natalis.

Lisheng D. (2005) China's Drive to Revitalize the Northeast, China Perspective. Available at: https://journals.openedition.org/chinaperspectives/462 (accessed 1 May 2020).

Lee R. (2005) Bauman, Liquid Modernity and Dilemmas of Development. Thesis Eleven, (83): 61-77.

Namsaraieva S. (2016) Gender and Trade in Russian - China Border City Manzhouli. Russian Studies, (3): 94-120.

Naughton B. (2007) The Chinese Economy. Transition and Growth. Cambridge: MIT Press.

Peshkov I. (2011) From 'Border Socialism' to 'Border Capitalism'. Past Dependency in the Inner Asia Border Triangle. Sensus Historiae. Studia Interdyscyplinarne, III (2): 139-149.

Peshkov I. (2014) Usable Past for a Transbaikalian Borderline Town. 'Disarmament' of Memory and Geographical Imagination in Priargunsk. Inner Asia, (16): 95-115.

Ryzhova N. (2008) Informal Economy of Translocations. The Case of Twin City of Blagoveshensk-Heihe. Inner Asia, (10):323-351.

Ryzhova N. (2018) The Emergence of Cross-Border Electronic Commerce Creativity and Declining Trust. In: C. Humphrey (ed.) Trust and Mistrust in the Economies of the China-Russian Borderlands. Amsterdam: Amsterdam University Press:229-250. 
Soi I., Nugent P. (2018) Peripheral Urbanism in Africa: Border Towns and Twin Towns in Africa. Journal of Borderlands Studies, 32 (4): 535-556.

Urbansky S. (2012) A Very Orderly Friendship: The Sino-Soviet Border under the Alliance Regime, 1950-1960. Eurasia Border Review, (3):35-53.

Volkov V.V. (2005) Silovoe predprinimatel'stvo. Ekonomiko-sotsiologicheskiy analiz [Violent Entrepreneurship in Russia. Economic and Sociological Analysis]. Moscow: GU WShE.

Zhang Ping-Yu, Ma Yan-ji, Yu Zhen-han (2002) Border port Manzhouli: Urban Function and Space Development. Chinese Geographical Science, 12 (4):315-320. 